\title{
Structural Concrete
}

Journal of the fib

\section{Effect of polymer modified cementitious coatings on chloride induced corrosion of steel in concrete}

\begin{tabular}{|c|c|}
\hline Journal: & Structural Concrete \\
\hline Manuscript ID & suco.201900255.R1 \\
\hline Wiley - Manuscript type: & Technical Paper \\
\hline $\begin{array}{r}\text { Date Submitted by the } \\
\text { Author: }\end{array}$ & $\mathrm{n} / \mathrm{a}$ \\
\hline Complete List of Authors: & $\begin{array}{l}\text { Brenna, Andrea; Politecnico di Milano, Chimica, Materiali e Ingegneria } \\
\text { Chimica G.Natta } \\
\text { Berra, Mario; Ricerca sul Sistema Energetico SpA, RSE } \\
\text { Beretta, Silvia; Politecnico di Milano, Chimica, Materiali e Ingegneria } \\
\text { Chimica G.Natta } \\
\text { Diamanti, Maria Vittoria; Politecnico di Milano, Chimica, Materiali e } \\
\text { Ingegneria Chimica G.Natta } \\
\text { Ormellese, Marco; Politecnico di Milano, Chimica, Materiali e Ingegneria } \\
\text { Chimica G.Natta } \\
\text { Pastore, Tommaso; Università degli studi di Bergamo, Dipartimento di } \\
\text { progettazione e tecnologie } \\
\text { Pedeferri, MariaPia; Politecnico di Milano, Chimica, Materiali e Ingegneria } \\
\text { Chimica G.Natta } \\
\text { Bolzoni, Fabio; Politecnico di Milano, Chimica, Materiali e Ingegneria } \\
\text { Chimica G.Natta }\end{array}$ \\
\hline Subject codes: & building materials | construction materials, reinforcement, corrosion \\
\hline Keywords: & concrete coatings, corrosion of reinforcements, chlorides diffusion \\
\hline Abstract: & $\begin{array}{l}\text { The paper deals with the study of the effect of polymer modified } \\
\text { cementitious mor-tars on chloride-induced corrosion of steel } \\
\text { reinforcement in concrete. Nowadays, many results obtained by standard } \\
\text { and short-term tests are available in the literature. The paper reports } \\
\text { more than } 15 \text { years exposure testing on two commercial coatings, with } \\
\text { different polymer/cement ratio. The effect of coatings on corrosion } \\
\text { initiation and propagation has been studied by the monitoring of } \\
\text { corrosion potential and corrosion rate of rebars in concrete subjected to } \\
\text { chloride ponding; chloride profiles, coating adhesion, water content and } \\
\text { corrosion morphology have been also analyzed. } \\
\text { It was demonstrated that polymer modified cementitious mortars can } \\
\text { delay corrosion initiation caused by chloride penetration into concrete. } \\
\text { Owing to high resistivity of coated concrete, corrosion rate is reduced. } \\
\text { The protective effect is more pronounced as the polymer content (p/c) } \\
\text { increases from } 0.35 \text { to } 0.55 \text {. The results have been elaborated to } \\
\text { estimate the possible increase of service life gained with this additional } \\
\text { protection method, compared with other solutions. }\end{array}$ \\
\hline
\end{tabular}




\section{SCHOLARONE ${ }^{\mathrm{m}}$ Manuscripts}




\title{
Effect of polymer modified cementitious coatings on chloride induced corrosion of steel in concrete
}

\author{
Andrea Brenna1, Silvia Beretta ${ }^{1}$, Mario Berra ${ }^{2}$, Maria Vittoria Diamanti' ${ }^{1}$, Marco \\ Ormellese ${ }^{1}$, Tommaso Pastore ${ }^{3}$, MariaPia Pedeferri ${ }^{1}$, Fabio Bolzoni ${ }^{1}$ \\ ${ }^{1}$ Politecnico di Milano, Dipartimento Chimica, Materiali e Ingegneria Chimica "Giulio \\ Natta", Milano, Italia \\ ${ }^{2}$ R.S.E. S.p.A. Ricerca sul Sistema Energetico, Milano, Italia \\ ${ }^{3}$ Università di Bergamo, Dipartimento di Ingegneria e scienze applicate, Dalmine
}

(BG), Italia

\section{Summary}

The paper deals with the study of the effect of polymer modified cementitious mortars on chloride-induced corrosion of steel reinforcement in concrete. Nowadays, many results obtained by standard and short-term tests are available in the literature. The paper reports more than 15 years exposure testing on two commercial coatings, with different polymer/cement ratio. The effect of coatings on corrosion initiation and propagation has been studied by the monitoring of corrosion potential and corrosion rate of rebars in concrete subjected to chloride ponding; chloride profiles, coating adhesion, water content and corrosion morphology have been also analyzed.

It was demonstrated that polymer modified cementitious mortars can delay corrosion initiation caused by chloride penetration into concrete. Owing to high resistivity of coated concrete, corrosion rate is reduced. The protective effect is more pronounced as the polymer content $(\mathrm{p} / \mathrm{c})$ increases from 0.35 to 0.55 . The results have been elaborated to estimate the possible increase of service life gained with this additional protection method, compared with other solutions.

\section{Introduction}

Rebar corrosion is one of the most important cause of premature failure of reinforced concrete structures. Steel reinforcements in concrete are in passive conditions, protected by a thin oxide layer, promoted by the concrete alkalinity (Bertolini, Elsener, Pedeferri, Redaelli, Polder, 2013; Pedeferri 2018). Depassivation may occur because of concrete carbonation, due to the reaction of atmospheric carbon dioxide with cement paste that lowers $\mathrm{pH}$ and causes general corrosion, and by the presence of chlorides in concentration higher than a critical level, that is generally considered in the range of $0.4-1 \%$ by cement weight for concrete structures exposed to atmosphere (Bertolini, Elsener, Pedeferri, Redaelli and Polder, 2013). Chlorides can be added erroneously into concrete through mixing water or aggregates or they can penetrate from external sources, by diffusion or capillary suction, for example in highway viaducts where de-icing salts are used, or in marine structures (Bertolini, Elsener, Pedeferri, Redaelli and Polder, 2013).

The prevention of reinforcement corrosion is primarily achieved in the design phase by using high quality concrete, adequate concrete cover and suitable casting and curing procedures (EN 206, Eurocode 2). Additional prevention methods are adopted when severe environmental conditions occur on structures requiring very long service life, as well as in repair and rehabilitation. 
Two phases can be identified in the service life of reinforced concrete structures subjected to corrosion, according to the Tuutti model: the initiation of corrosion, during which $\mathrm{CO}_{2}$ or chlorides penetrate the concrete cover, reaching the reinforcement and depassivating carbon steel, and the propagation phase, where corrosion takes place in presence of oxygen and water (Tuutti, 1982). The end of the corrosion propagation period corresponds to serviceability limit states, that can be defined as loss of adhesion rebar-concrete, concrete cracking or spalling, reduction of rebar cross section (Beck et al., 2012; Osterminski and Schiessl, 2012; von GreveDierfeld and Gehlen, 2016; Andrade, Cesetti, Mancini and Tondolo, 2016). The service life can be guaranteed by increasing both the initiation and the propagation time. In general, the increase of initiation time is more viable and reliable, especially in the case of chloride induced corrosion, since localised corrosion rate can be very high and propagation time very short (Bertolini, Elsener, Pedeferri, Redaelli, Polder, 2013).

Concrete surface treatments are of great interest for protection of reinforced concrete structure as an alternative to more expensive preventative techniques, as well as in rehabilitation (Swamy and Tanikawa, 1993; Basheer, Basheer, Cleland and Long, 1997; Sergi, Seneviratne, Maleki, Sadezgadeh and Page, 2000; Raupach and Wolff, 2004). Nowadays various surface treatments are available, suitable for maintaining their protectiveness for long-time and for a good service life, providing that a proper application and an adequate maintenance are assured.

It is possible to distinguish four main classes of surface treatments for concrete: (a) organic coatings that form a continuous film (Swamy, Suryanvanshi and Tanikawa, 1998; Aguiar, Camoes and Moreira, 2008), (b) hydrophobic treatments that line the surface of the pores (de Vries and Polder, 1997; Tittarelli and Moriconi, 2008), (c) treatments that fill the capillary pores (Moon, Shin and Choi, 2007) and (d) cementitious layers (Coppola, Pistolesi, Zaffaroni and Collepardi, 1997; Kristiansen, 1997; Aggarwal, Thapliyal and Karade 2007).

The paper deals with the study of coatings based on polymer modified cementitious mortars applied on the concrete surface in order to protect reinforcement against corrosion in chloride containing environment. These coatings have good adhesion, flexibility and also show a considerable "crack-bridging" ability due to their low elastic modulus. Furthermore, they show low water permeability and an adequate vapor transpiration to avoid high pressures at the concrete/coating interface, which can induce cracks or breaking of the coating. Their high inorganic content provides high UV-ray resistance. Literature data emphasizes coating properties concerning water absorption, water and water vapour permeability, steady-state chlorides diffusion, adhesion, crack-bridging, accelerated corrosion tests (Coppola, Pistolesi, Zaffaroni and Collepardi, 1997; Zhang and Buenfeld, 2000; Al-Zhahrani, Dulajian, Ibrahim, Saricimen and Sharif, 2002). There is a lack of data about long-term behaviour, only few papers report some of these results (Kristiansen, 1997; Raupach and Wolff, 2004; Aggarwal, Thapliyal and Karade 2007; Brenna, Bolzoni, Beretta and Ormellese 2013; Sadati, Arezoumadi, Shekarchi, 2015).

In a previous paper water absorption, water vapour permeability, steady-state chloride diffusion and coating-concrete adhesion were measured with the aim to understand the mechanisms by which coating can prevent or control corrosion (Diamanti, Brenna, Bolzoni, Berra, Pastore, Ormellese 2013). The main results are summarised below: 
- reduction of water content and chloride penetration into concrete under wet and dry condition; due to the good water vapour permeability coatings are also able to reduce significantly the water content in external exposure

- the protective effect is improved when the polymer-to-cement ratio increases.

In this paper, more than 15 years exposure testing on two commercial coatings, with different polymer/cement ratio, are reported. The effect of the coatings has been studied by monitoring of the corrosion behaviour of reinforced concrete specimens subjected to chloride ponding: corrosion potential, corrosion rate and chloride profile have been carried out. At the end of the exposure adhesion coating- concrete and corrosion morphology after concrete breaking have been evaluated on specimens coated with the coating with $\mathrm{p} / \mathrm{c} 0.35$.

\section{Experimental}

\subsection{Materials}

Laboratory tests were performed on commercial cementitious coatings (mortars), modified with the addition of acrylic-based polymer. Mortars were cast with Ordinary Portland Cement, W/C ratio 0.5 , and silica sand particles. Two commercial coatings were tested, with a polymer-to-cement $(\mathrm{p} / \mathrm{c})$ ratio of 0.35 and 0.55 , respectively.

Coatings were applied on reinforced concrete specimens $(70 \cdot 160 \cdot 250 \mathrm{~mm}$, Figure 1) cast with cement type CEM II A/L 42,5R (according to EN 197/1) and crushed calcareous aggregates with $10 \mathrm{~mm}$ maximum size (Zandobbio Quarry - BG, Italy). Water/cement $(\mathrm{W} / \mathrm{C})$ ratio is 0.5 . Concrete cover is $20 \mathrm{~mm}$. Concrete mixture proportion is reported in Table 1. Two specimens were cast for each condition: without coatings and with the two coatings.

Carbon steel bars with $10 \mathrm{~mm}$ diameter were used. Only $170 \mathrm{~mm}$ of bar were exposed to concrete, while the protruding extremes of the bar were isolated by a heat-shrinkable sheath (Figure 1). For the corrosion rate measurements a stainless steel type AISI 304 wire was embedded as reference electrode and two bars of stainless steel AISI 304 were also embedded in concrete as counter electrodes (Figure 1).

Concrete specimens were cured for 28 days at $20^{\circ} \mathrm{C}$ and $95 \%$ relative humidity. Compressive strength was measured on $100 \mathrm{~mm}$ side concrete cubes after 28 days curing (Table 1). After curing, concrete specimens were maintained for two months at $20^{\circ} \mathrm{C}$ and $50 \%$ relative humidity. Then concrete surfaces were hard bristle brushed in order to eliminate any loose matter and assure a good adherence of coatings. The two commercial coatings were applied with a thickness of about $2 \mathrm{~mm}$ on all the sides of the specimens.

\subsection{Monitoring of corrosion potential and corrosion rate}

Concrete specimens were exposed indoor in the laboratory atmosphere (temperature $20^{\circ} \mathrm{C} \pm 5^{\circ} \mathrm{C}$ ) and subjected to accelerated chloride penetration, i.e. ponding cycles. A ponding cycle consist of one week wetting with a $5 \%$ sodium chloride solution (almost $30,000 \mathrm{mg} / \mathrm{L}$ chloride ions), and two weeks drying. Two liters of the test solution were placed in contact with the upper surface of the specimen by putting the solution in a plastic box fixed on the top of the sample.

Steel reinforcements corrosion was monitored by open circuit potential $\left(E_{c o r r}\right)$ measurement with respect to an external saturated calomel reference electrode (SCE, +0.244 $\mathrm{V} \mathrm{SHE)} \mathrm{and} \mathrm{by} \mathrm{linear} \mathrm{polarization} \mathrm{resistance} \mathrm{(LPR)} \mathrm{measurement}$ 
(Andrade and Gonzalez, 1978). Corrosion current density $\left(\mathrm{i}_{\text {corr }}, \mathrm{mA} / \mathrm{m}^{2}\right)$ is related to the specific LPR $\left(\Omega \cdot \mathrm{m}^{2}\right)$ by Stern-Geary equation (Andrade and Gonzalez, 1978):

Eq. $1 \quad i_{C O R R}=\frac{B}{L P R}$

where B is the Stern-Geary coefficient (related to anodic and cathodic Tafel slopes) which assumes approximately a value of $26 \mathrm{mV}$ or $52 \mathrm{mV}$ for steel in active or passive condition, respectively. For iron, the corrosion current density in $\mathrm{mA} / \mathrm{m}^{2}$ can be converted in corrosion rate ( $\mu \mathrm{m} /$ year) by multiplying a factor about 1.2. LPR measurement was carried out applying a potential scan in the range $\pm 10 \mathrm{mV}$ with respect to $E_{\text {corr }}$ with a scan rate of $0.16 \mathrm{mV} / \mathrm{s}$. The polarization current was supplied by means of two stainless steel counter-electrodes placed on both sides of the reinforcement (Figure 1). During LPR test, potential was measured with respect to the internal AISI 304 reference electrode, in order to minimize the ohmic drop contribution. Corrosion rate can be considered negligible if it is lower than 1-2 $\mu \mathrm{m} /$ year (Andrade, 2003).

\subsection{Measurement of total chloride content}

Concrete chloride profiles were determined on $30 \mathrm{~mm}$ diameter cores drilled from the specimens. Cores were cut into $10 \mathrm{~mm}$ slices that were subsequently crushed and dissolved in nitric acid. The solution was then analyzed by potentiometric titration with $\mathrm{AgNO}_{3}$.

\subsection{Analysis at the end of exposure}

After about 14 years of exposure, the specimens where rebars suffered corrosion (with $0.35 \mathrm{p} / \mathrm{c}$ coating) were broken to analyze the presence and morphology of corrosion, the corrosion rate, the concrete-coating adhesion and the concrete water content.

\subsubsection{Concrete water content}

Four concrete specimens were extracted near to the rebar. Specimens were dried at $105^{\circ} \mathrm{C}$ and then immersed in water until a constant weight was reached.

Water content, $\mathrm{W}_{\mathrm{c}}(\%$ in weight) and pore saturation degree, PS (\%), were calculated as follows:

Eq. 2a $w_{c}=\frac{m-m_{0}}{m_{0}}$
Eq. $2 \mathrm{~b}$
P.S. $=\frac{m-m_{0}}{m_{s}-m_{0}}$

where $m$ is the weight at the end of the exposure, $m_{0}$ is the oven dried weight, and $m_{s}$ is the water saturated weight.

\subsubsection{Coating adhesion}

Adhesion tests between coatings p/c 0.35 and concrete were performed after 14 years exposure according to ASTM D4541 standard. The pull-off test was performed by securing a loading fixture perpendicular to the top surface of the specimen with an adhesive. After the adhesive was cured, a testing apparatus was attached to the 
loading fixture and aligned to apply a tension normal to the test surface. The force applied to the loading fixture is gradually increased and monitored, until a plug of material was detached. The nature of the failure is qualified in accordance with the percent of the adhesive and cohesive failures, and the actual interface and layer involved. Three tests for each specimen were carried out.

\subsubsection{Rebar visual inspection and corrosion rate}

At the end of the tests, rebars were extracted from concrete specimens for visual inspection and corrosion rate evaluation. This latter was carried out in two different ways: weight loss measurements (average value of corrosion rate) and laser profilometry (localized corrosion rate of the deepest localized attacks). Before these analyses, corrosion products were removed from the base metal by a chemical pickling procedure in solution with $18 \%$ hydrochloric acid and $3.5 \mathrm{~g} / \mathrm{L}$ hexamethylene tetramine (ASTM G1 standard). Weight loss has been estimated as the difference between the weight per unit length of rebars in contact with concrete and the uncorroded rebars. Weight was measured by an analytical balance (accuracy \pm 0.001 $\mathrm{g})$, and rebar length were measured by a comparator $( \pm 0.01 \mathrm{~mm})$.

\section{Results}

\subsection{Corrosion monitoring}

The reinforcing bars of uncoated specimens suffered corrosion initiation during first cycles of exposure (Figure 2 and Figure 3). Free corrosion potential of the rebars drops to about $-400 \mathrm{mV}$ vs SCE, i.e. active values according to the literature (Bertolini, Elsener, Pedeferri, Redaelli, Polder, 2013; Elsener, Andrade, Gulikers, Polder and Raupach, 2003; ASTM C876). In the same time, corrosion rate increased above $10 \mathrm{~mA} / \mathrm{m}^{2}$ (corresponding to about $10 \mu \mathrm{m} /$ years of mean corrosion rate), which is well higher than the negligible value of $2 \mathrm{~mA} / \mathrm{m}^{2}$ (Andrade, 2003).

In concrete with $0.35 \mathrm{p} / \mathrm{c}$ coating, the lowering of potential was noticed on both the specimens after about 3.5 years, indicating a possible corrosion initiation. Nevertheless, corrosion rates remained negligible. In these specimens, the corrosion rate increased over $2 \mathrm{~mA} / \mathrm{m}^{2}$ only after about 9 years.

Specimens covered by $0.55 \mathrm{p} / \mathrm{c}$ coating show passive reinforcement until about 17 years testing (high values of corrosion potential and negligible corrosion rate).

Concrete electrical resistance has been measured after 6 years, giving an estimation of concrete resistivity around $600 \Omega \cdot \mathrm{m}$ in concrete with $0.35 \mathrm{p} / \mathrm{c}$ coating, and $2 \mathrm{k} \Omega \cdot \mathrm{m}$ in concrete with $0.55 \mathrm{p} / \mathrm{c}$ coating. The first value is typical of concrete in environments with intermediate water content while the second of low water content.

\subsection{Chloride content}

The coatings are able to reduce the chloride content in specimens subjected to chloride ponding (Figure 4) and the effect is enhanced for the coating with higher p/c ratio. The data are in agreement with those presented in a previous paper (Diamanti, Brenna, Bolzoni, Berra, Pastore and Ormellese, 2013), where in steady-state chloride diffusion, the application of a $2 \mathrm{~mm}$ thick coating was "equivalent" to an increase of concrete cover (with the same w/c ratio 0.5 ) of about $9 \mathrm{~mm}$ and $23 \mathrm{~mm}$ for coating 0.35 and $0.55 \mathrm{p} / \mathrm{c}$, respectively. 
After 58 cycles ( 3 years 8 months approx.), the chloride content at the depth of steel bars $(20 \mathrm{~mm})$ was only $0.1 \%$ and $0.02 \%$ (by concrete weight) in the specimens covered by the coating with 0.35 and $0.55 \mathrm{p} / \mathrm{c}$, respectively, compared to a chloride content of about $0.26 \%$ reached in the uncoated specimens after only 38 cycles $(2.4$ years), see Figure 4.

The results for one specimen with coating p/c 0.35 are shown in Figure 4 (right): chloride content increases with time.

In the specimens coated with $\mathrm{p} / \mathrm{c} 0.55$ the chloride content remained lower than $0.1 \%$ by concrete weight even after 170 cycles (around 9.4 years).

\subsection{Analysis at the end of exposure}

After more than 14 years of exposure, the specimens coated with $p / c=0.35$ coating were broken in order to analyze the morphology of corrosion, the corrosion rate, the concrete-coating adhesion and the concrete water content.

\subsubsection{Concrete water content}

Water content and pore saturation degree were evaluated according to Eq. 2 (a-b). Four measurements for each specimen were carried out. Mean values of water content and pore saturation degree are between 1.8 and $2.0 \%$ and between $44 \%$ and $50 \%$, respectively (Table 2 ).

Considering Figure 5, the pore saturation degree in concrete $(\mathrm{W} / \mathrm{C}=0.5)$ coated with $\mathrm{p} / \mathrm{c} 0.35$, after 14.7 years of accelerated chloride transport, is higher than the values measured in the same combination of concrete and coating after three years of atmospheric exposure. The pore saturation in concrete coated with p/c 0.35 is also close to values measured in the same concrete $(\mathrm{W} / \mathrm{C}=0.5)$ uncoated after three years of atmospheric exposure (Diamanti, Brenna, Bolzoni, Berra, Pastore and Ormellese, 2013). This trend can be attributed to the fact that after long time ponding water can overpass coating and enter into concrete. This is in agreement with the measurements reported in a previous paper (Diamanti, Brenna, Bolzoni, Berra, Pastore and Ormellese, 2013). After immersion in water, in concrete with coating p/c 0.55 the water content was lower and not influenced by concrete w/c ratio $(0.5$ or 0.6). In the specimens with coating p/c 0.35 the water content after immersion was higher in more porous concrete (0.6), and this difference can be attributed to the water penetration into concrete.

\subsubsection{Coating adhesion}

Adhesion was measured on the top surface after 14.7 years exposure. The values of mean adhesion strength are in the range 0.51-0.63 MPa (Table 3), similar or higher than the values measured after three years of atmospheric exposure on both coatings with p/c 0.35 and 0.55 (Diamanti et al. 2013). In most cases, the failure occurred at the interface between coating and concrete. On the other hand, macroscopic delamination of coatings has been observed at the edge of the specimen, mainly at the bottom.

\subsubsection{Rebar visual inspection and corrosion rate}

At the end of the tests, rebars were extracted from concrete specimens and severe pitting corrosion attacks surrounded by passive steel surface were observed. After the removal of corrosion products rebars were sliced and corrosion rate for each portion was calculated as explained in par. 2.4.3. Mass loss is converted in thickness 
loss and corrosion rate is defined as the ratio between the thickness loss (assuming general corrosion) and the corrosion propagation time, after the stable increase of corrosion rate. For all the specimens, mean corrosion rate is below $10 \mu \mathrm{m} / \mathrm{y}$, in fair agreement with the values calculated by linear resistance polarization technique (Figure 6).

The localized corrosion rate have been calculated as the ratio between corrosion depth and the corrosion propagation time. The localized corrosion rates are much higher than the general corrosion ones (Figure 6). The ratio between the values corresponding to $50 \%$ cumulative frequency for general and localized corrosion rate is about 10, in agreement with the values found by other researchers (Gonzalez et al 1995).

\section{Discussion}

\subsection{Initiation of corrosion}

It is evident from the data presented in Figures 2-3 that the presence of coatings is able to delay significantly the onset of corrosion in concrete subjected to accelerated chloride transport (ponding). The time of initiation of corrosion, evaluated when corrosion potential was significantly lowered is reported in Table 4 for concrete without coating and concrete with coating p/c 0.35. In concrete with coating p/c 0.55 corrosion was not initiated even after 17 years (the date of the last measurement of corrosion potential and corrosion rate). The delay of corrosion initiation can be due to:

- slowing chloride transport in concrete

- increase of the critical chloride content

In our case, it is expected that the first is the most influencing factor. In the following the results are analysed and discussed to verify this hypothesis.

\subsubsection{Chloride transport}

Chlorides penetration in concrete is due to the presence of different mechanisms, mainly diffusion and capillary sorption. Nevertheless, for comparison purposes, experimental profiles were interpolated using the analytical solution of the Fick's second law of diffusion. This approach was proposed first by $\mathrm{M}$. Collepardi and coauthors in 1972 (Collepardi, Marcialis and Turriziani, 1972).

Assuming the chlorides content at the concrete surface (Cs) constant with time, considering an effective chloride diffusion coefficient $\left(D_{\text {eff }}\right)$ constant in time and space (i.e. concrete is homogeneous and its properties do not vary with time), and a semiinfinite diffusion length, the analytical solution of the Fick's 2nd law is:

Eq. $3 \quad \frac{C(x, t)}{C_{s}}=1-e r f\left(\frac{x}{2 \sqrt{D_{\text {eff }} \cdot t}}\right)$

where erf is the error function, $\mathrm{C}(\mathrm{x}, \mathrm{t})$ is the chloride content at the depth $\mathrm{x}$ and time $\mathrm{t}$ and the initial chloride content in concrete has been fixed equal to 0 (Bertolini, Elsener, Pedeferri, Redaelli and Polder. 2013).

For comparison purposes, the experimental chloride profiles (Figure 4) have been interpolated by fitting the (Eq. 3) by non-linear regression. By using this approach, the presence of two different materials (concrete and coating) is neglected and the 
calculated $D_{\text {eff }}$ can be considered as a "pseudo" diffusion coefficient, representative of both concrete and coating "in series". The other parameter evaluated by nonlinear regression is $C_{s}$, which represent the chloride concentration at the concrete surface. This value could be considered constant in the case of concrete without coating, but this is not the case for coated concrete: in this case, $\mathrm{C}_{\mathrm{s}}$ increases with time. Consequently, the calculated $D_{\text {eff }}($ Table 3 ) has to be considered a regression parameter: the measured value decreases from $14 \cdot 10^{-12} \mathrm{~m}^{2} \cdot \mathrm{s}^{-1}$ for concrete W/C 0.5 not coated (reproducible for the measurements taken at different times) to values generally lower for concrete coated with p/c 0.35 mortar. It is not possible to calculate the value of $D_{\text {eff }}$ for the concrete coated with p/c 0.55 mortar, because chloride concentration is very low and the chloride profile is nearly flat.

To verify the influence of coatings on the chlorides transport, $\mathrm{C}_{\mathrm{s}}$ values must also be compared (Table 5 and Figure 4 ): after 38 ponding cycles (2.4 years), $\mathrm{C}_{\mathrm{s}}$ was $0.54 \%$ by concrete weight in untreated concrete; in the presence of coating $\mathrm{p} / \mathrm{c} 0.35$ lower values $(0.46 \%)$ were measured after 107 cycles (9.5 years). Only after 170 cycles (13.5 years) $\mathrm{C}_{\mathrm{s}}$ became higher $(0.64-0.76 \%)$.

\subsubsection{Critical chloride content}

Critical chloride threshold was calculated taking into account the measured time-tocorrosion (Table 4) by using the parameters obtained by chloride profile interpolation $\left(D_{\text {eff }}\right.$ and $C_{s}$ in Table 5). For concrete without coating, critical chloride threshold is $0.06 \%$ by concrete weight, that correspond for the considered mix to about $0.48 \%$ by cement weight, in agreement with the ranges reported in literature, $0.4-1 \%$ by cement weight (Bertolini, Elsener, Pedeferri, Redaelli and Polder, 2013). In the case of coated concrete with $\mathrm{p} / \mathrm{c} 0.35$ coating, considering the initiation of corrosion when potential drop was observed, a similar value was found, about $0.06-0.08 \%$ by concrete weight.

\subsection{Propagation of corrosion}

In this paper, the limit state corresponds to corrosion initiation: this is a conservative approach, taking into account that the chloride induced corrosion is localized and the propagation period of corrosion could be very short (Bertolini, Elsener, Pedeferri, Redaelli and Polder, 2013). Nevertheless, we performed some analysis also referred to the propagation of corrosion.

In concrete with coating p/c 0.35 , corrosion initiation was detected after 3.5 years, while a stable increase of corrosion rate (above $2 \mathrm{~mA} / \mathrm{m}^{2}$ ) was observed only after 9 years. To explain the trend of the corrosion rate we can make two hypothesis: the influence of water (and chloride) content or the amount of corroded area. Concerning the first hypothesis, we can suppose that during the first period of exposure concrete water content was low, and this can be explained by the high value of concrete resistivity $(600 \Omega \mathrm{m})$ measured after 6 years exposure, while water content increased significantly in time, as evident by the measurement after 14.7 years (Figure 5). These findings are confirmed by the measurement of chloride content: in the same concrete with coating p/c 0.35 the value was relatively low $(<0.1 \%$ by concrete mass) after 3.7 years and much higher after 9 years, i.e. $0.2-0.3 \%$ by concrete mas.

Another possible explanation of the corrosion rate trend is related to the amount of corroded area. The measured value of LPR consider the whole surface of the rebar, and it is inversely proportional to the mean value of corrosion rate. After corrosion initiation, the corroded area can be initially very low and also the mean value of 
corrosion rate is low, so the LPR remains high. The corroded area, and the mean value of corrosion rate increase in time and accordingly the LPR is reduced.

In the Figure 6 , it has been shown that in concrete with p/c 0.35 coating, the average corrosion rate are in the range 5-10 $\mu \mathrm{m} /$ year. It should be pointed out that these values can be misleading: pitting corrosion is localized on small portion of surface and the maximum pitting corrosion rate is much higher, in the range of 100-300 $\mu \mathrm{m} /$ year, as shown in Figure 6 . Both the general corrosion and the localized corrosion rate measured in this work are comparable to those found in a previous work (Ormellese, Berra, Bolzoni and Pastore, 2006), in the same concrete without coating both in the case of chloride ponding or with mixed-in chlorides $(1.5 \%$ and $2.5 \%$ by cement mass).

\section{Effect of concrete coatings on service life}

In this section, a first attempt to characterise the behaviour of concrete coated with polymer-modified cementitious mortars is carried out by probabilistic performance based approach (FIB Model Code 2006; Bertolini, Elsener, Pedeferri, Redaelli and Polder, 2013).

Probabilistic performance based approaches are able to take into account the intrinsic variability of the influencing factors. This approach has been implemented in different models, among these the best known is the Model code for service life design, issued by the International federation for concrete (FIB) in 2006. Service life (equal to initiation time of corrosion, $t_{i}$ ) is evaluated according to the eq. 3 . The failure probability $\left(P_{f}\right)$ is the probability that a serviceability limit state is exceeded:

$$
P_{f}=P\left[\left(C_{x}\left(d, t_{i}\right)>C_{c r}\right)\right]
$$

The application of a probabilistic performance based approach, simpler than FIB Model Code, is proposed in this paper. Monte Carlo simulation was applied to evaluate the distribution of the initiation time of corrosion. The complete results of these analyses are reported in previous papers (Bolzoni et al. 2016; Ormellese et al. 2018) here the methodology and main results are summarized. The use of coatings is compared with concrete manufactured with CEM III and other additional protection methods, like stainless steel rebars or corrosion inhibitors.

Cathodic prevention can be used as reference: in fact, if properly applied it is able to tolerate a very high chloride content and so corrosion never initiate (Pedeferri 1996; Bertolini, Bolzoni, Gastaldi, Pastore, Pedeferri and Redaelli 2009), provided monitoring and maintenance of the system (current feeder, connection cables or anodes) are properly scheduled and performed.

The evaluation of the $t_{i}$ requires the definition of the distribution of the influencing parameters, considered as random variables: surface chloride content $\left(C_{s}\right)$, chloride diffusion coefficient $D_{\text {eff, }}$ critical chloride content $\left(C_{\text {critical }}\right)$ and concrete cover $(d)$.

\subsection{Surface chloride content.}

No clear indication are given in the Fib Model Code, so distribution has been selected based on literature. For the exposure class XS3 the values suggested in the paper (Lollini, Carsana, Gastaldi, Redaelli, Bertolini 2015) are considered; for the exposure class XS1 the values were halved (Table 6). In the presence of coatings, the chloride concentration $\mathrm{C}_{\mathrm{s}}$ is reduced, according to the results of this paper: mean 
value $3 \%$ and standard deviation $1.2 \%$ in zone XS3; mean value $1.5 \%$ and standard deviation $0.6 \%$ in zone XS1.

\subsection{Concrete cover depth.}

Normal distribution has been selected according to Fib Model Code: mean values were selected for each exposure class according to the Eurocode, while the standard deviation was fixed at $10 \mathrm{~mm}$ (Lollini, Carsana, Gastaldi, Redaelli, Bertolini 2015), see Table 6.

\subsection{Chloride diffusion coefficient.}

The mean values have been selected based on literature, considering long term measurements for concrete with w/c ratio 0.45 and manufactured with CEM I or CEM III. Lognormal distribution have been selected (Table 2). In presence of the coating, diffusion coefficient is reduced by $30 \%$, according to the results presented in this paper (Table 7).

\subsection{Critical chloride threshold.}

For carbon steel rebar, in agreement with the fib Model Code, Beta distribution with mean value $0.6 \%$ by cement mass and standard deviation $0.15 \%$ has been selected. Since no information are available in the fib Model Code, for the preventative techniques the same distribution has been used, with different mean values and standard deviation, mainly based on literature (Bertolini et al 2013, Gastaldi et al 2014, Elsener 2001, Ormellese at el 2006, Ormellese et al 2008, Bolzoni et al 2014). For stainless steels reinforcement traditional type EN 1.4307 that correspond to the classical AISI 304L has been considered, the most used for reinforcements (Gastaldi, Lollini and Bertolini 2014). Table 8 reports all values.

\subsection{Estimation of service life}

Before to discuss the results of the simulation is very important to notice that they have to be considered as an example of calculation and they cannot be generalised. First, the results of the simulation depend on the input parameters. In a real case, they can vary according to the design and execution. For example, concrete cover can be estimated or measured in significant locations, surface chloride concentration can be related to previous experience in the same exposure, chloride diffusion coefficient can be measured by accelerated testing and corrected with an aging factor, as suggested in FIB Model code (2006). Concerning concrete coating, sufficient data are available only for $\mathrm{p} / \mathrm{c} 0.35$ so the parameter of the simulation are representative of this case. For both concrete coatings and corrosion inhibitors, only one application is considered: in the real case, the results could be improved by subsequent applications.

Values of relevant factors (surface and critical chloride, diffusion coefficient, cover depth) are obtained by means of extraction of random numbers, using the distributions reported in Tables 6-8. The single value of the service life (initiation time of corrosion $t_{i}$ ) is calculated by means of the Equation 3 . After the repetition of this procedure for 1000 times, the probability distribution of service life is obtained by Monte Carlo simulation (Cheldi, Cavassi, Lazzari, Pezzotta 1995).

In the Figure 7, the results of the simulation are shown. The horizontal line corresponds to a failure probability $\left(P_{f}\right) 10 \%$, suggested by the FIB Model Code for serviceability limit state of depassivation (FIB Model code 2006). The vertical line correspond to the target lifetime 50 years according to Eurocode for building or other 
common structures, while 100 years (maximum of the service life range) is the target for bridges and infrastructures.

In spite of the limitations reported at the beginning of this paragraph, the results of the simulation evidence some interesting information and can be used for comparison purposes. Concrete coatings are able to improve the performance vs not coated concrete: nevertheless, the improvement is not enough to reach with sufficient reliability the target life of 50 years, especially in more aggressive exposure classes (XS3). The use of CEM III instead of CEM I could reduce $P_{f}$, but not enough: values lower than $10 \%$ for 50 years can be guaranteed only increasing the concrete cover vs the minimum value reported in the Eurocode 2.

The service life target could be obtained only by the use of more effective (and more expensive) additional protection like the stainless steels rebars: in severe conditions (XS3) failure probability remains lower than $10 \%$ for at least 80 years if the mean cover depth is $45 \mathrm{~mm}$. By combining stainless steel with concrete cast with CEM III the performance could be improved even more.

In this paper, the analysis of the Life Cycle Cost (LCC) has not been performed; as a first approximation, even though both stainless steel reinforcements and cathodic prevention increase significantly the investment costs, from the service life results it can be deduced that they decrease significantly the repair and maintenance costs. In addition, the use of concrete coatings in severe exposure can be explored, with the aim to reduce the repair and maintenance works: this option can reduce the Life Cycle Cost, as shown for hydrophobic treatment applied to concrete in a bridge deck exposed to de-icing salts (Polder, Pan, Courage, Peelen 2016).

\section{Conclusions}

The effectiveness of two concrete coatings, based on a polymer modified cementitious mortar, has been verified by means of 17 year-long corrosion monitoring:

- these coatings can strongly delay chloride-induced corrosion initiation and this effect is mostly related to the effect on chloride transport

- owing to higher resistivity (lower water and chloride content) of coated concrete, corrosion rate can be reduced

- the protective effect is more pronounced as the polymer content (p/c) increases. By combining the experimental results of this paper with literature data and probabilistic performance based methods, the impact of cementitious-polymeric coatings on the reinforced concrete service life has been investigated. Even if the impact is not so strong if compared to other additional protection methods (as stainless steel reinforcements), especially in very aggressive environments, the use of coatings can reduce the need of repair and maintenance works.

\section{References}

Aggarwal L.K., Thapliyal P.C., Karade S.R. (2007). Properties of polymer-modified mortars using epoxy and acrylic emulsions, Construction and Building Materials 21, 379-383.

Aguiar J.B., Camões A., Moreira P.M., Coatings for concrete protection against aggressive environments, J. Adv. Concr. Techn. 6 (2008) 243-250.

https://doi.org/10.3151/jact.6.243 
Al-Zahrani M.M., Al-Dulaijan S.U., Ibrahim M., Saricimen H., Sharif F.M. (2002). Effect of waterproofing coatings on steel reinforcement corrosion and physical properties of concrete. Cement \& Concrete Composites 24, 127-137.

Andrade C., Gonzalez J.A. (1978). Quantitative measurements of corrosion rate of reinforcing steels embedded in concrete using polarization resistance measurements, Werkstoffe und Korrosion 29 (8), 515-519. https://doi.org/10.1002/maco.19780290804

Andrade C. (2003). Determination of chloride threshold in concrete, in Corrosion of steel in reinforced structures, Final Report, COST action 521. Luxembourg: Office for Official Publications of the European Communities, 2003, 108-119.

Andrade C., Cesetti A., Mancini G., Tondolo F. Estimating corrosion attack in reinforced concrete by means of crack opening (2016) Structural Concrete 17 (4) pp. 533-540 (DOI: 10.1002/suco.201500114

ASTM D4541 (2010). Standard Test Method for Pull-Off Strength of Coatings Using Portable Adhesion Testers.

ASTM C876 (2009), Standard test method for corrosion potentials of uncoated reinforcing steel in concrete.

ASTM G1 (2011), Standard practice for preparing, cleaning, and evaluating corrosion test specimens, ASTM International.

Basheer P.A.M., Basheer L., Cleland D.J., Long A.E. (1997). Surface treatments for concrete: assessment methods and reported performance. Construction and Building materials 10 , 413-429. https://doi.org/10.1016/S0950-0618(97)00019-6

Beck, M., Burkert, A., Harnisch, J., Isecke, B., Osterminski, K., Raupach, M., SchießI, P., Tian, W., Warkus, J., (2012). Deterioration model and input parameters for reinforcement corrosion. Structural Concrete, 13 (3), pp. 145-155. DOI: 10.1002/suco.201200004

Bertolini L., Bolzoni F., Gastaldi M., Pastore T., Pedeferri P. and Redaelli E. (2009). Effects of cathodic prevention on the chloride threshold for steel corrosion in concrete 2009. Electrochimica Acta 54 1452-1463. 10.1016/j.electacta.2008.09.033

Bertolini L., Elsener B., Pedeferri P., Redaelli E. \& Polder R. (2013), Corrosion of steel in concrete - Prevention, diagnosis, repair (2nd Ed), Weinheim: Wiley VCH. DOI: $10.1002 / 9783527651696$

Bolzoni F., Brenna A., Fumagalli G., Goidanich S., Lazzari L., Ormellese M. \& Pedeferri M.P., 2014. Experiences on corrosion inhibitors for reinforced concrete. Int. J. Corros. Scale Inhib. 3, no. 4, 254-278. DOI 10.17675/2305-6894-2014-3-4-254278

Bolzoni F., Beretta S., Brenna A., Diamanti M.V., Lazzari L., Ormellese M. and Pedeferri M.P. (2016). Evaluation of additional protection methods to control reinforcement corrosion, Proc. of Int. Conf. Concrete under severe conditions, Key Engineering materials, Switzerland: Trans Tech publications, 37-46. https://doi.org/10.4028/www.scientific.net/KEM.711.37

Brenna A., Bolzoni F., Beretta S., Ormellese M. (2013). Long-term chloride-induced corrosion monitoring of reinforced concrete coated with commercial polymer-modified mortar and polymeric coatings, Construction and Building Materials 48, 734-744. http://dx.doi.org/10.1016/j.conbuildmat.2013.07.099 
CEN EN 206-1 ( 2000). Concrete - Part 1: Specification, performance, production and conformity.

CEN EN 1992-1-1 (2004). Eurocode 2: Design of concrete structures - Part 1-1: General rules and rules for buildings.

Cheldi T, Cavassi P, Lazzari L., Pezzotta L. (1997). Use of decision tree analysis and Montecarlo simulation for downhole material selection, Proc. Of Corrosion/97 Conference, Houston: Nace International, Paper 97018.

Collepardi M., Marcialis A. and Turriziani R. (1972). Penetration of chloride ions into cement pastes and concretes Journal of American Ceramic Society, 55: 534-535.

Coppola L., Pistolesi C., Zaffaroni P., Collepardi M. (1997). Properties of polymercement coatings for concrete protection, Proc. of Fifth Canmet-ACl Int. Conf. "Superplasticizers and other chemical admixtures in concrete", ACI SP 173, Roma, Italy, 267-286.

CEN EN 197-1, Cement - Part 1: Composition, specifications and conformity criteria for common cements

Diamanti M.V., Brenna A., Bolzoni F., Berra M., Pastore T., Ormellese M. (2013).

Effect of polymer modified cementitious coatings on water and chloride permeability in concrete, Construction and Building Materials 49, 720-728.

https://doi.org/10.1016/j.conbuildmat.2013.08.050

Elsener B. (2001). Corrosion inhibitors for steel in concrete - an EFC state of the art report, London: Institute of Materials and European Federation of Corrosion, Number 35.

Elsener, B., Andrade, C., Gulikers, J., Polder R., Raupach M. (2003) . Half-cell potential measurements - Potential mapping on reinforced concrete structures, Materials and Structures 36, 461-471. https://doi.org/10.1007/BF02481526

Gastaldi M., Lollini F., Bertolini L., (2014). Performance-based durability design of reinforced concrete structures with stainless steel bars, Metallurgia Italiana, 106 (78), 17-21.

Gonzalez J.A., Andrade C., Alonso C., Feliu S. (1995). Comparison of rates of general corrosion and maximum pitting penetration on concrete embedded steel reinforcement. Cem Concr Res 25, 257-64 https://doi.org/10.1016/00088846(95)00006-2

International Federation for Structural Concrete, FIB (2006). Model code for service life design, Bulletin n. 34.

Kristiansen B. (1997). Protective coatings applied in coastal climate. Materials, application, performance, Proc. of Int. Conf. Repair of concrete structures. From theory to practice in a marine environment, Svolvaer, Norway, 485-499.

Lollini F., Carsana M., Gastaldi M., Redaelli E., Bertolini L. (2015). The challenge of the performance-based approach for the design of reinforced concrete structures in chloride bearing environment, Construction and Building Materials 79, 245-254 http://dx.doi.org/10.1016/j.conbuildmat.2014.12.044

Lollini F., Gastaldi M. \& Bertolini L. (2018). Performance parameters for the durability design of reinforced concrete structures with stainless steel reinforcement, Structure and Infrastructure Engineering, 14:7, 833-842. DOI: 10.1080/15732479.2018.1436573. 
Moon H.Y., Shin D..G., Choi D.S. (2007). Evaluation of the durability of mortar and concrete applied with inorganic coating material and surface treatment system, Constr. Build. Mater. 21, 362-369. https://doi.org/10.1016/j.conbuildmat.2005.08.012

Ormellese M., Berra M., Bolzoni F., Pastore T. (2006) Corrosion inhibitors for chlorides induced corrosion in reinforced concrete structures, Cement and Concrete Research 36 (2006) 536 - 547. https://doi.org/10.1016/j.cemconres.2005.11.007

Ormellese M., Bolzoni F., Lazzari L., Pedeferri P. (2008) Effect of corrosion inhibitors on the initiation of chloride-induced corrosion on reinforced concrete structures. Mater Corros 59, 98-106. https://doi.org/10.1002/maco.200804155

Ormellese M., Beretta S., Brenna A., Diamanti M.V., Pedeferri M.P., Bolzoni F. (2018). Additional protection systems to control reinforcement corrosion, Structural 219, paper 19.

Osterminski, K., Schießl, P. (2012). Design model for reinforcement corrosion Structural Concrete, 13 (3), pp. 156-165 DOI: 10.1002/suco.201200003

Pedeferri P 1996 Cathodic protection and cathodic prevention. Construction and building materials 10 (5), 391-402. https://doi.org/10.1016/0950-0618(95)00017-8

Pedeferri $P$ (2018). Corrosion science and engineering, ed L Lazzari and MP Pedeferri, Cham, Switzerland: Springer Nature.

Polder, R., Pan, Y., Courage, W., Peelen, W., (2016). Preliminary study of life cycle cost of preventive measures and repair options for corrosion in concrete infrastructure, Heron 61 (1), 1-13.

Raupach, M., Wolff, L. (2004). Long-term durability of surface protection systems over concrete, Journal of Protective Coatings and Linings 21 (6), 29-37.

Sadati S., Arezoumandi M., Shekarchi M., (2015). Long-term performance of concrete surface coatings in soil exposure of marine environments, Construction and Building Materials 94, 656-663

Sergi G., Seneviratne A.M.G., Maleki M.T., Sadegzadeh M., Page C.L., Control of reinforcement corrosion by surface treatment of concrete. Proc Inst Civil Eng: Struct Build 2000;140(1):85-100. https://doi.org/10.1680/stbu.2000.140.1.85

Swamy R.N. \& Tanikawa S. (1993). An external surface coating to protect concrete and steel from aggressive environments, Materials and Structures 26 465-478. https://doi.org/10.1007/BF02472806

Swamy, R.N., Suryavanshi, A.K., Tanikawa, S. (1998). Protective ability of an acrylicbased surface coating system against chloride and carbonation penetration into concrete, ACI Materials Journal, 95 (2),101-112.

Tittarelli F., Moriconi G. (2008). The effect of silane-based hydrophobic admixture on corrosion of reinforcing steel in concrete, Cement and Concrete Research 38, 13541357. DOI: 10.1016/j.cemconres.2008.06.009

Tuutti K (1982). Corrosion of steel in concrete, Stockolm: Swedish foundation for concrete research

von Greve-Dierfeld, S., Gehlen, C. Performance based durability design, carbonation part 1 - Benchmarking of European present design rules (2016) Structural Concrete, 17 (3), pp. 309-328 DOI: 10.1002/suco.201600066

de Vries, J. Polder, R.B. (1997). Hydrophobic treatment of concrete, Construction and Building Materials 11 (4), 259-265. DOI 10.1016/S0950-0618(97)00046-9 
Zhang J.Z., Buenfeld N.R. (2000). Chloride profiles in surface-treated mortar specimens, Constr. Build. Mater. 14, 359-364. 
Table 1: Concrete mix design and mechanical properties.

\begin{tabular}{|l|l|}
\hline Cement content $\left(\mathrm{kg} / \mathrm{m}^{3}\right)$ & 300 \\
\hline Water/cement ratio $(\mathrm{w} / \mathrm{c})$ & 0.5 \\
\hline Aggregates $\left(\mathrm{kg} / \mathrm{m}^{3}\right)$ & 2000 \\
\hline Plasticizer $\left(\mathrm{kg} / \mathrm{m}^{3}\right)$ & 4.5 \\
\hline 28 days compressive strength (MPa) & 46 \\
\hline
\end{tabular}

Table 2: Water content and pore saturation degree (mean values) of coated concrete.

\begin{tabular}{|c|c|c|c|}
\hline p/c & Specimen & $\mathbf{W}_{\mathbf{c}}$ (\% in weight) & P.S. (\%) \\
\hline \multirow{2}{*}{0.35} & 1 & 1.8 & 46 \\
\cline { 2 - 4 } & 2 & 2.0 & 50 \\
\hline
\end{tabular}

Table 3: Results of adhesion tests according to ASTM D4541.

\begin{tabular}{|c|c|c|c|c|c|}
\cline { 3 - 6 } \multicolumn{2}{c|}{} & \multicolumn{4}{c|}{ Adhesion strength (MPa) } \\
\hline p/c & Specimen & $\mathbf{1}^{\text {st }}$ & $\mathbf{2}^{\text {nd }}$ & $\mathbf{3}^{\text {rd }}$ & Mean \\
\hline \multirow{2}{*}{0.35} & 1 & 0.61 & 0.71 & 0.36 & $\mathbf{0 . 5 6}$ \\
\cline { 2 - 6 } & 2 & 0.66 & 0.71 & 0.51 & $\mathbf{0 . 6 3}$ \\
\hline
\end{tabular}

Table 4: Results of corrosion monitoring of concrete W/C 0.5 with or without coating.

\begin{tabular}{|c|c|c|c|}
\multicolumn{2}{c}{} & \multicolumn{2}{c|}{ Initiation of corrosion } \\
\hline p/c & Spec & Cycle & Time \\
\hline \multirow{2}{*}{ No coating } & 1 & 3 & 2 months \\
\cline { 2 - 4 } & 2 & 5 & 3 months \\
\hline 0.35 & 2 & 53 & 3.4 years \\
\hline & 3 & 53 & 3.4 years \\
\hline
\end{tabular}

Table 5: Transport properties of concrete W/C 0.5 with or without coating

\begin{tabular}{|c|c|c|c|c|}
\hline $\mathbf{p} / \mathbf{c}$ & Spec. & Ponding cycle & $\mathbf{D}_{\text {eff }}\left(\mathbf{1 0}^{-\mathbf{1 2}} \mathbf{~}^{\mathbf{2}} \cdot \mathbf{s}^{-\mathbf{1}}\right)$ & $\mathbf{C}_{\mathbf{s}}(\mathbf{\%}$ vs concrete) \\
\hline- & 1 & 4 & 13.9 & 0.35 \\
\hline- & & 38 & 14.5 & 0.54 \\
\hline 0.35 & 1 & 58 & 8.2 & 0.14 \\
\hline \multirow{2}{*}{0.35} & 1 & 107 & 3.6 & 0.46 \\
\cline { 2 - 5 } & 2 & 107 & 10.1 & 0.46 \\
\hline 0.35 & 1 & 170 & 5.1 & 0.64 \\
\hline & 2 & 170 & 14.3 & 0.76 \\
\hline
\end{tabular}

Table 6 Values of parameters used for Monte Carlo simulation ( $\mathrm{C}_{\mathrm{s}}$ and cover depth)

\begin{tabular}{|c|c|c|c|}
\hline \multicolumn{2}{|c|}{} & $\begin{array}{c}\text { Marine exposure, } \\
\text { atmospheric (XS1) }\end{array}$ & $\begin{array}{c}\text { Marine exposure, } \\
\text { splash/tidal (XS3) }\end{array}$ \\
\hline $\begin{array}{c}\text { Surface chloride content } \\
\left(\mathbf{C}_{\mathbf{s}}\right)[\% \text { by cement mass] } \\
\text { Lognormal }\end{array}$ & Mean value & $2.5 \%$ & $5 \%$ \\
\cline { 2 - 4 } & Std deviation & $1 \%$ & $2 \%$ \\
\hline $\begin{array}{c}\text { Concrete cover }[\mathrm{mm}] \\
\text { Normal }\end{array}$ & Mean value & 35 & 45 \\
\cline { 2 - 4 } & Std deviation & 10 & 10 \\
\hline
\end{tabular}


Table 7 Diffusion coefficient $\left(D_{\text {eff }}\right)$ used for Monte Carlo simulation (concrete w/c $0.45)$

\begin{tabular}{|l|c|c|c|c|}
\hline \multirow{2}{*}{\multicolumn{2}{|c|}{}} & \multicolumn{2}{|c|}{ CEM I } & CEM III \\
\cline { 3 - 5 } \multicolumn{2}{|c|}{$\begin{array}{c}\text { No } \\
\text { coating }\end{array}$} & Coating & $\begin{array}{c}\text { No } \\
\text { coating }\end{array}$ \\
\hline $\begin{array}{l}\mathbf{D}_{\text {app }}\left[10^{-12} \mathrm{~m}^{2} / \mathrm{s}\right] \\
\text { Lognormal distribution }\end{array}$ & Mean value & 1 & 0.7 & 0.2 \\
\cline { 2 - 5 } & Std deviation & 0.2 & 0.14 & 0.04 \\
\hline
\end{tabular}

Table 8 Critical chloride content used for Monte Carlo simulation

\begin{tabular}{|l|c|c|c|c|}
\hline \multicolumn{2}{|c|}{} & Carbon steel & $\begin{array}{c}\text { Stainless steel } \\
\text { AISI 304 }\end{array}$ & $\begin{array}{c}\text { Corrosion } \\
\text { inhibitor }\end{array}$ \\
\hline $\begin{array}{l}C_{\text {critical }}[\% \text { by cement mass] } \\
\text { Beta distribution }\end{array}$ & Mean value & 0.6 & 5 & 1.2 \\
\cline { 2 - 5 } & Std deviation & 0.15 & 1.25 & 0.3 \\
\hline
\end{tabular}




\section{Figure captions}

Figure 1: Cross section and lateral view of reinforced concrete specimen.

Figure 2: Free corrosion potential of rebars in concrete subjected to accelerated chloride ponding.

Figure 3: Corrosion rate of rebars in concrete subjected to accelerated chloride ponding.

Figure 4: Chloride profile in concrete subjected to chloride ponding: comparison of coated and not coated specimens (left) and evolution in time for one specimen with p/c 0.35 coating (right).

Figure 5: Concrete pore saturation at the end of exposure (14 years) and comparison with the data after 3 years in atmosphere from previous paper (Diamanti et al. 2013).

Figure 6: Cumulative frequency of the general corrosion rate (left) and localised corrosion rate (right) in specimens with $\mathrm{p} / \mathrm{c} 0.35$ coating

Figure 7: Cumulative distribution of the failure probability: example of calculation by means of Monte Carlo simulation: exposure class XS3, mean cover $45 \mathrm{~mm}$ (left), exposure class XS1, mean cover $35 \mathrm{~mm}$ (right), parameters of the distributions in Tables 6-8 (adapted from Bolzoni et al. 2016; Ormellese et al. 2018) 


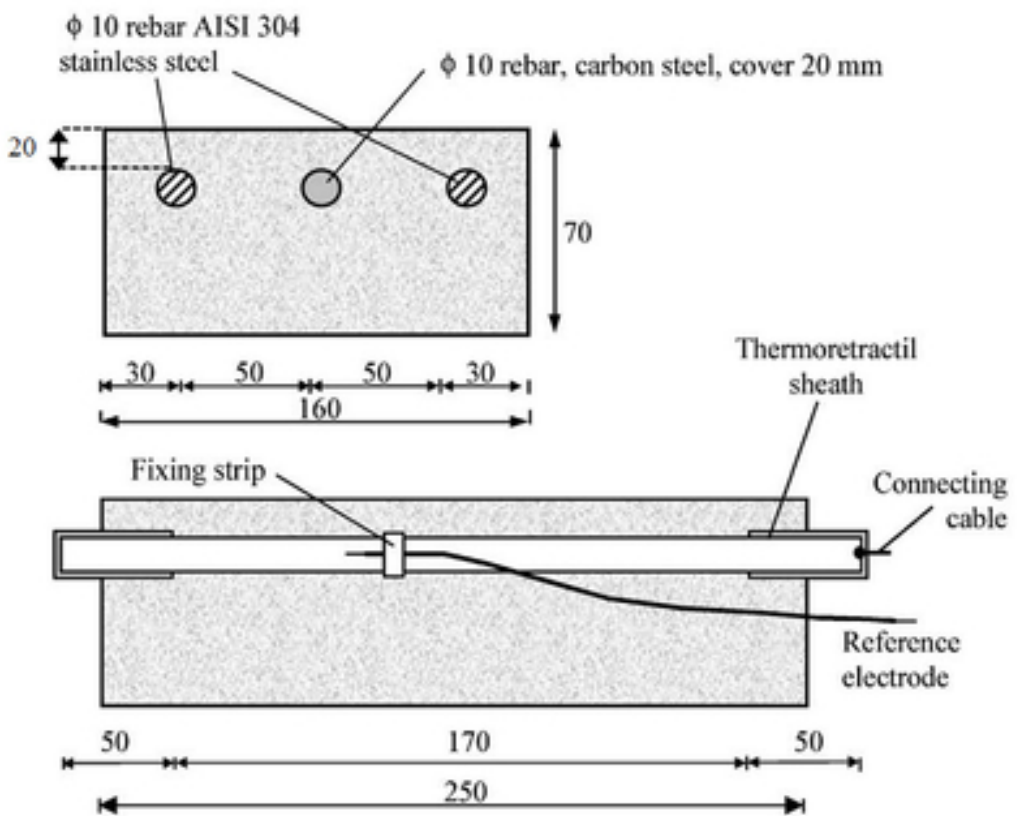

Figure 1

$17 \times 15 \mathrm{~mm}(600 \times 600 \mathrm{DPI})$ 


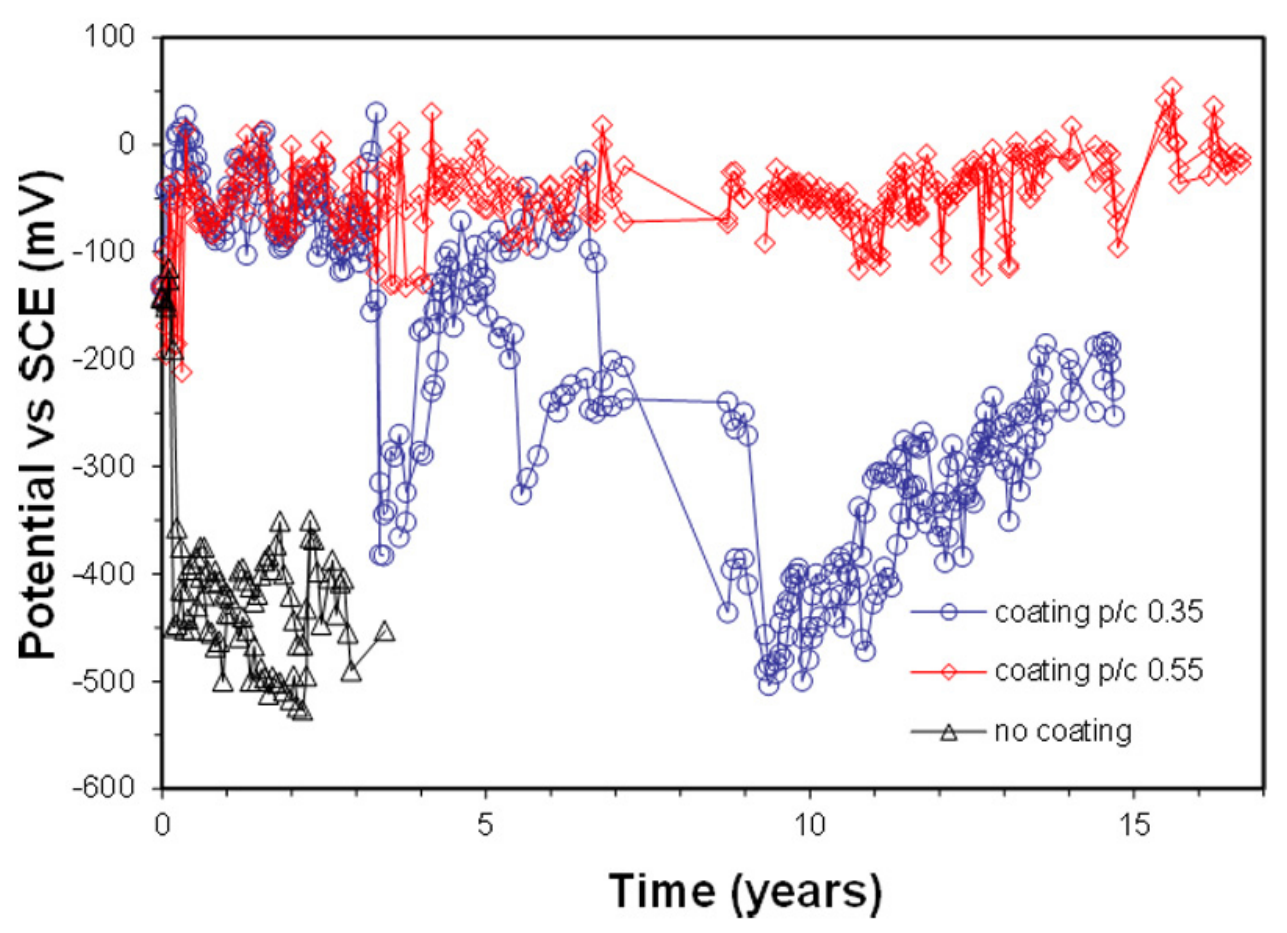

Figure 2

$141 \times 101 \mathrm{~mm}(150 \times 150 \mathrm{DPI})$ 


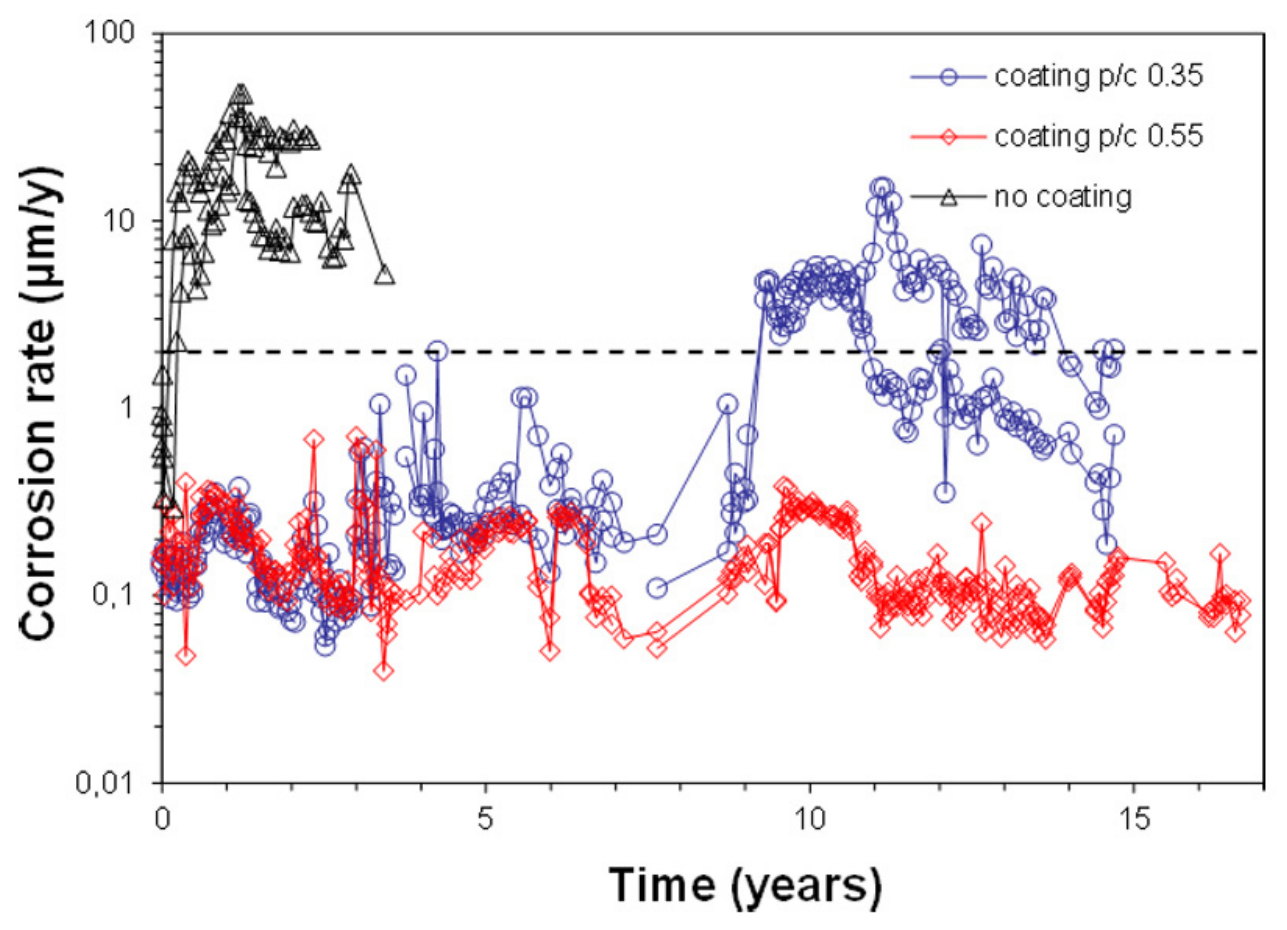

Figure 3

$141 \times 101 \mathrm{~mm}(150 \times 150 \mathrm{DPI})$ 

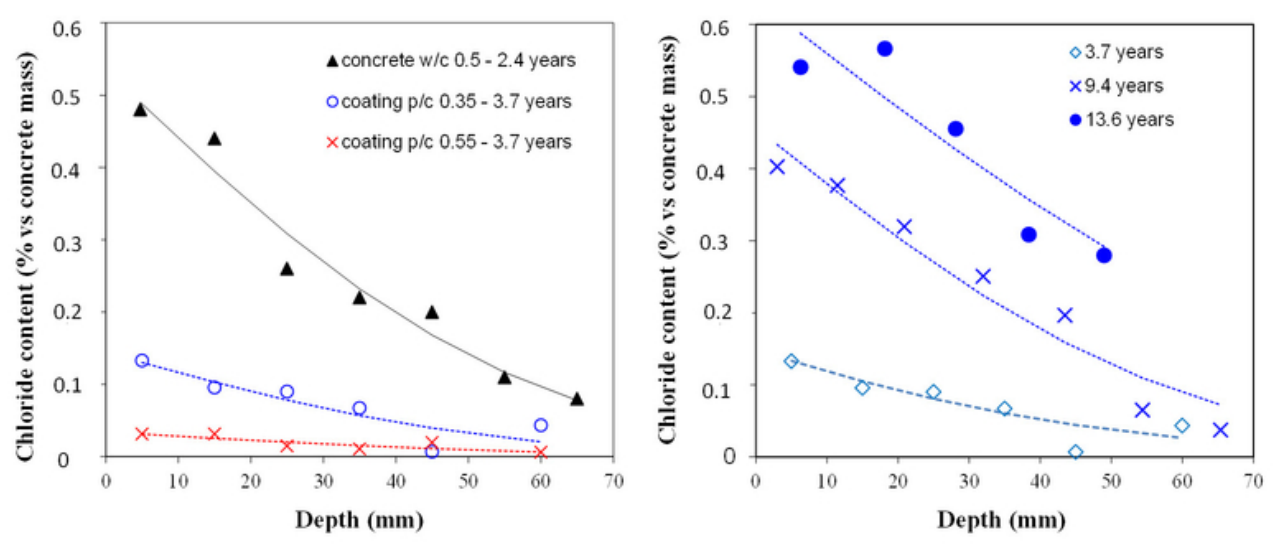

Figure 4

$33 \times 14 \mathrm{~mm}(600 \times 600$ DPI $)$ 


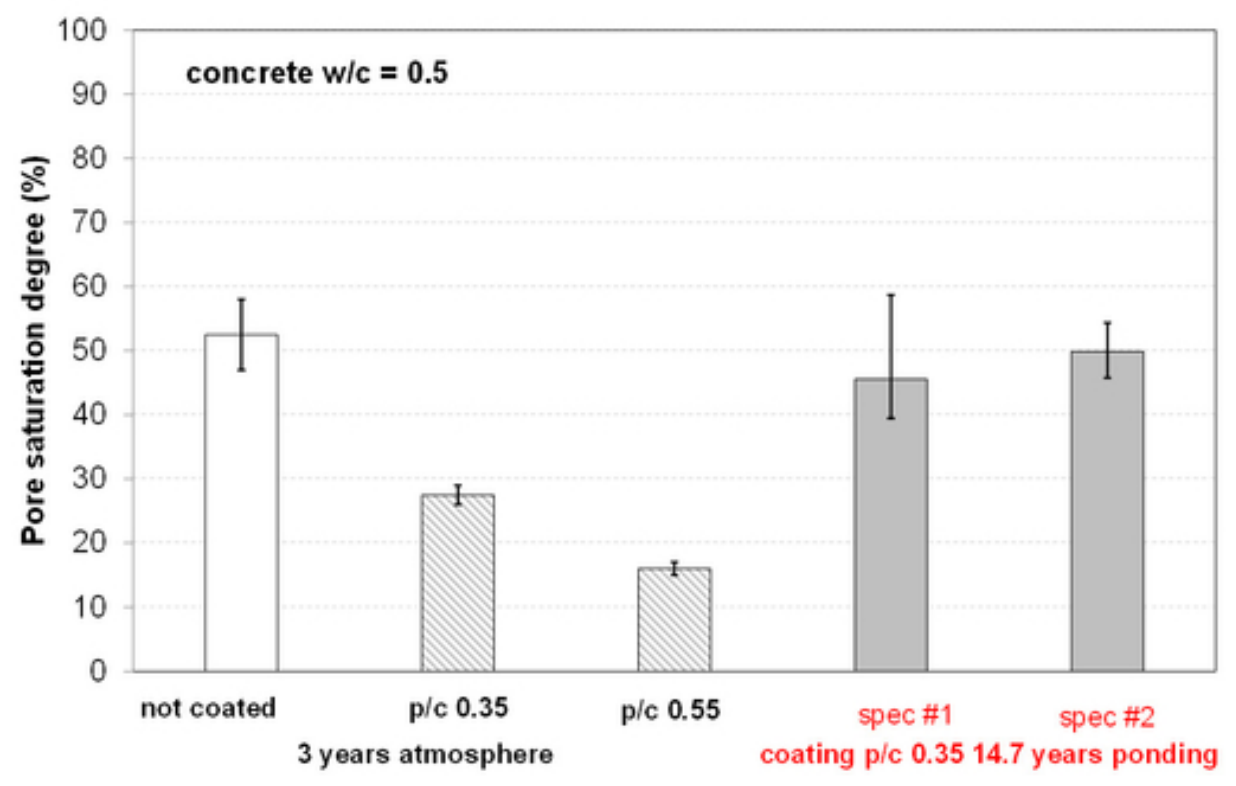

Figure 5

$23 \times 15 \mathrm{~mm}(600 \times 600$ DPI $)$ 

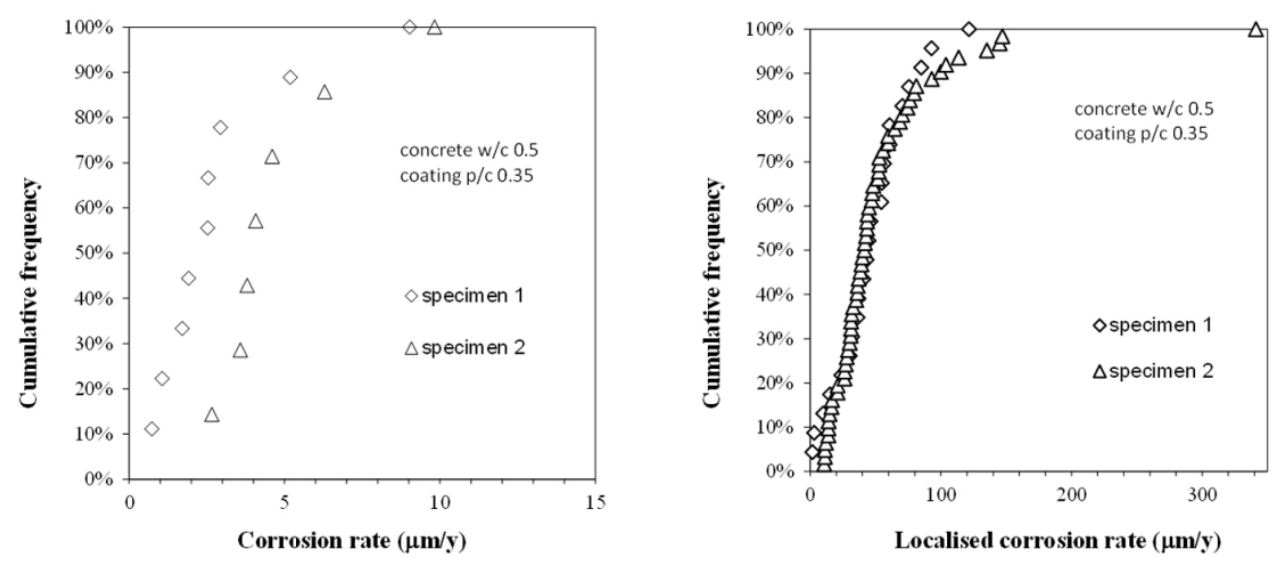

Figure 6

$243 \times 101 \mathrm{~mm}(150 \times 150 \mathrm{DPI})$ 

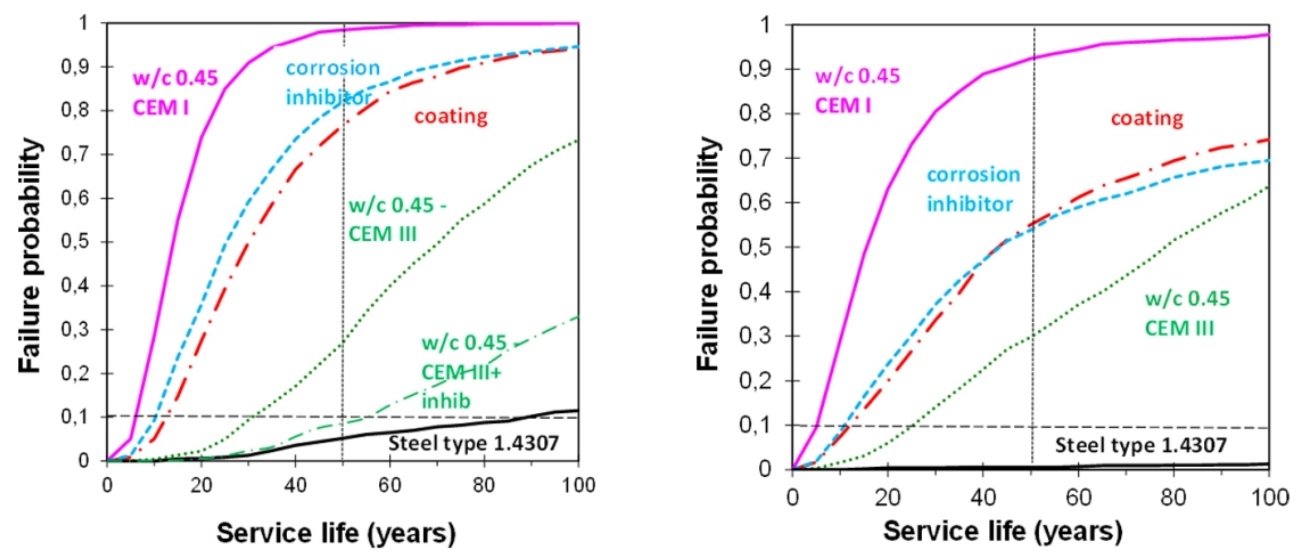

Figure 7

$239 \times 101 \mathrm{~mm}(150 \times 150 \mathrm{DPI})$ 